\title{
Effects of Steaming and Steam Explosion on Mechanical Properties of Snake Fruit (Salacca) Fiber
}

\author{
Seno Darmanto ${ }^{\# 1}$, Heru SB Rochardjo ${ }^{* 2}$ Jamasri $^{* 3}$, Ragil Widyorini ${ }^{\square 4}$ \\ \# Doctoral S3 of Department of Mechanical and Industrial Engineering, Universitas Gadjah Mada \\ Lecture of Department of Industrial Engineering, Vocation School, Universitas Diponegoro \\ *Department of Mechanical and Industrial Engineering, Universitas Gadjah Mada \\ ${ }^{\square}$ Department of Forest Product Technology, Universitas Gadjah Mada \\ J1. Grafika No. 2, Yogyakarta, 55281, Indonesia \\ ${ }^{1}$ senodarmanto@gmail.com \\ ${ }^{2}$ heru-sbr@ugm.ac.id \\ 3 jamasri@ugm.ac.id \\ ${ }^{4}$ rwidyorini@gmail.com
}

\begin{abstract}
Application of natural fiber needs treatments, such as chemical, physical and mechanical treatments. The aim of these treatments is for getting purer, cleaner and smaller size cellulose fiber. This paper describes the treatment of Snake Fruit frond fiber using alkali, steaming and steam explosion and investigates the effects on mechanical properties. The single fiber was firstly subjected to alkali treatments with $2 \%-8 \%$ NaOH for 2 - 8 hours to room temperature and steaming in 1 - 2 bar. The tensile test of single fiber was done according to standard ASTM D3379. The tensile tests show that the alkali and steaming treatment resulted in the different tensile strength of Snake Fruit frond fiber compared those without soaking. The highest tensile strength was found at Snake Fruit front fiber immersed in $2 \%$ $\mathrm{NaOH}$ for 6 hours and steaming 2 bars. The strength also increases with combination treatment both alkali-steaming and alkali-steam explosion with starting from $160 \mathrm{MPa}$ before treated, increases as high as $275 \mathrm{MPa}$ and $225 \mathrm{MPa}$ with alkali-steaming and alkali-steam explosion, respectively. These results show that the combination of alkali treatment, steaming and steam explosion can significantly increase mechanical properties of Snake Fruit frond fiber.
\end{abstract}

Keyword: Snake Fruit frond fiber, alkali treatment, steaming, steam explosion, tensile strength

\section{INTRODUCTION}

Nowadays, the utilization of natural fiber has spread from household appliances, fashion and handicraft to transportation vehicles (including ground and air transportation vehicles). The fiber may come from stem, leaves, frond, and fruit. The potential uses of the frond of Snake Fruit (Salacca Zalacca) are quite large and have not been explored. Most of the benefit of Snake Fruit is consisted its fruit. However, the abundantly available leaf fronds of this crop, which are usually buried or burned, are possible to be applied more economically through the development of natural fiber composite. The benefits potential can also be extracted from impurity materials include seeds, skins, and frond. In general, the absorption potential uses of the impurities of Snake Fruit is still relatively low, and the average is used for fuel, even discarded and left to rot.

Application of natural fibers commercially for fiber composites and textiles has fluctuated. The need for application of natural fiber to facilities and infrastructure (equipment) that come into contact directly or indirectly with humans has increased sharply today. An increased natural fiber needs at present is closely related to people's demands for health, environmental issues and state policies. Several studies of synthetic fiber applications indicate that the equipment is made of synthetic fibers, and asbestos fibers contain substances implicated carcinogen [1]. The use of the reinforcing material to increase frictional force includes a lead oxide $(\mathrm{PbO})$ and metal oxide (metal oxide) [2] pollutes the air that interferes with the respiratory tract and eye irritation [1]. There are indications that the substances of carcinogenic cause cancer. Furthermore, environmental issues are driven by environmental groups which have encouraged the rejection and termination of the use of synthetic and mineral fibers. Application of synthetic fibers and mineral waste are difficult to decompose and pollute the environment include plastics, synthetic rubber, asbestos, and fiber glass. The policy of certain countries, especially the developed countries will be environmentally friendly technology has pushed the objections of some people to use synthetic fibers and minerals that are not environmentally friendly. Awareness of the negative effects of the use of synthetic fibers and mineral fibers automatically also has urged the international community to re-use equipment sourced from either natural fibers from plants and animals (natural fiber). By products of agricultural/plantation rind namely cashew have been applied as reinforcement in composite materials capable of friction [2]. Development of natural fibers as textile fibers and composites 
(including Snake Fruit frond fiber) will certainly increase the value of both technical and economically benefits. And further, the development of other Snake Fruit impurity materials (seeds, skins, and stems or leaf frond) will promote and support the competitiveness of the Snake Fruit main products.

Natural fiber reinforcement by chemical treatment results relatively well. Chemical treatment of natural fibers can be done by soaking or dipping into solution (solution) group containing hydroxide (OH) [3] [4], silica $(\mathrm{Si})$ [3] [4] [5][6], chloride ( $\mathrm{Cl})$ [4] and other coatings group, along with the treatment process conditions. Methods of treatment with a solution of alkali hydroxide are commonly called alkali treatment [3] [4]. Furthermore, chemical treatment with a solution containing a silicon group is called silane treatment [3] [4] [6]. Next chemical treatment using a solution containing chloride group is called benzoylation treatment [4]. Further treatment process conditions can be done by adjusting the concentration of the solution, temperature, time, stirring, and $\mathrm{pH}$. Enhancement the concentration of alkaline in treatment will increase the strength of the color difference [7]. Research flax fibers treated with $5 \%$ alkaline concentration on the variation of immersion time 0 , $2,4,6$ hours and the test results showed that they has an optimum level of the fibers treatment during 2 hours with $190.27 \mathrm{MPa}$ in strength and $0.44 \%$ in tensile strain. Furthermore, the weight loss test on the condition of the working temperature to $300^{\circ} \mathrm{C}$ showed no decrease in weight loss of $17 \%$ for the untreated fibers to $4 \%$ for flax fiber with alkali treatment and $0.5 \%$ to $2 \%$ for flax fibers treated with alkali to $5 \%$ [8]. Alkali treatment with $10 \%$ on flax fibers in composition has increased tensile strength, modulus Young, and impact strength $53.4 \mathrm{MPa}, 7.86 \mathrm{GPa}$ and $10.47 \mathrm{~kJ} / \mathrm{m}^{2}$ to $60.18 \mathrm{MPa}, 9.21 \mathrm{GPa}$ and $13.09 \mathrm{~kJ} / \mathrm{m}^{2}$, respectively [8]. In this paper, the chemical treated Snake Fruit frond fiber was further treated mechanically through both steaming and steam explosion process to get better performance.

\section{Materials AND Methods}

\section{A. Materials}

Raw Snake Fruit frond fiber was obtained from Snake Fruit agricultural in Sleman, Yogyakarta, Indonesia The chemicals used for extraction of fiber are $\mathrm{NaOH}$, and distilled water. Then, there were few apparatus that used in the research. They involved fiber processing, premature treatment, physical treatment, chemical treatment and the preparation of the specimen. The tools for fiber handling comprise of saws, knives, scissors, coarse steel brushes, steel brushes smooth, rolling and dryer. Then physical treatment equipment consisted of a stainless steel pan, square-shaped glass vessels of various sizes, heating, steaming, and steam explosion apparatus. The implement for the chemical treatment covered glass flask, beaker glass, measuring glass, a square-shaped glass vessels of various sizes, glass bowl, a small pan, viper stirrer, heater and temperature measuring devices. Next, the instrumentations of making specimen were be composed of cardboard, scissors, knives, steel ruler, and adhesives.

\section{B. Fibrillation and Purifying Method}

1) Fibrillation into Micrometer Scale: First, the Snake Fruit fronds were visually selected by basing old level and green color. They are taken and cut along $1 \mathrm{~m}$ from base point. Next, the each Snake Fruit frond was broken down into a single fiber. Single fiber fibrillation was done through several stages of work includes the selection frond stems, cutting to size $50 \mathrm{~cm}$, cleavage, soaking, drying, brushing and the separation of a single fiber to the other components.

2) Treatment of Low-Pressure Steaming: After first treating by submersion with distilled water and forced drying in an oven, a single fiber was then steamed at 1 bar in pressure for 60 minutes.

3) Alkali Treatment: The mechanism of alkali treatment was done through several stages including the preparation of a single fiber, the preparation of $2 \%-8 \%$ sodium hydroxide solution, dipping of a single fiber in the sodium hydroxide solution during $2-8$ hours, forced drying of the single fiber at $80^{\circ} \mathrm{C}-90^{\circ} \mathrm{C}$ and fiber storage.

4) Continued Steaming: The second steaming of the single fiber was in principle done by passing the saturated steam pressure of 2 bars and detention during 60 minutes.

5) Steam Explosion Treatment: First, the fiber that done by continued steaming was reduced into $2 \mathrm{~mm}$ in length. Then the small fiber was flowed steam in steam explosion apparatus at 5 bars in pressure and 25 times of released steam rapidly.

\section{Chemical Analysis}

The composition of single fiber was tested by standard gravimetric to analyze the effect of treatment on the content of cellulose, hemicellulose, and lignin. 


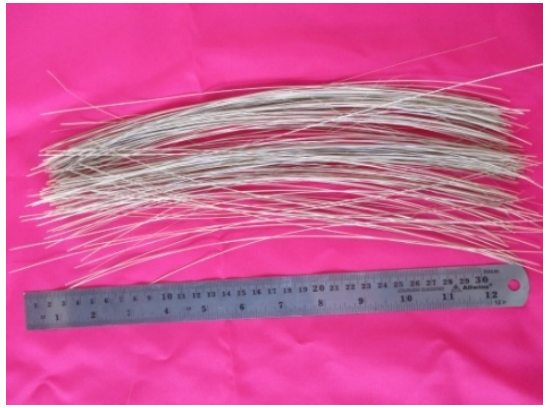

(a)

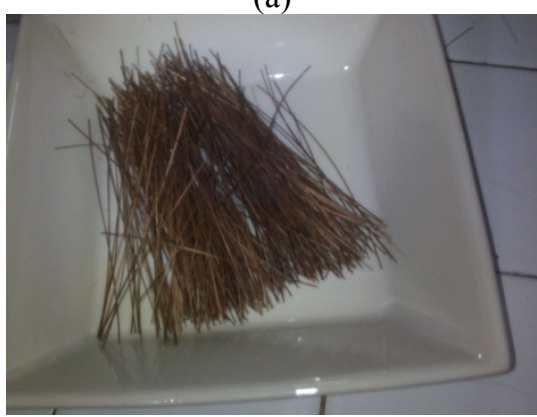

(c)

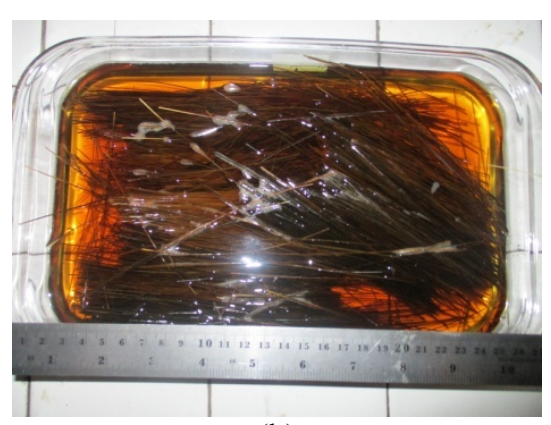

(b)

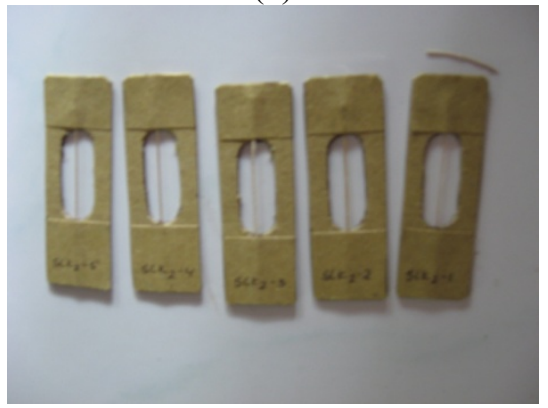

(d)

Fig. 1. Some research stages of Snake Fruit frond (a) pure Snake Fruit frond fiber, (b) submersion in a solution of sodium hydroxide, (c) single fiber after steaming, (d) tensile test specimens.

\section{Scanning electron microscopy (SEM) morphological}

The scanning electron microscopy was done to note data of morphology of untreated and steam exploded fibers.

\section{E. Tensile Test of Single Fiber}

The single fiber of Snake Fruit frond had then been tested the strength. Every variation of tensile test specimens was prepared some five specimens and then selects three specimens that provide the best testing results. Standard of fiber tensile test specimens refers to ASTM standard D3379.

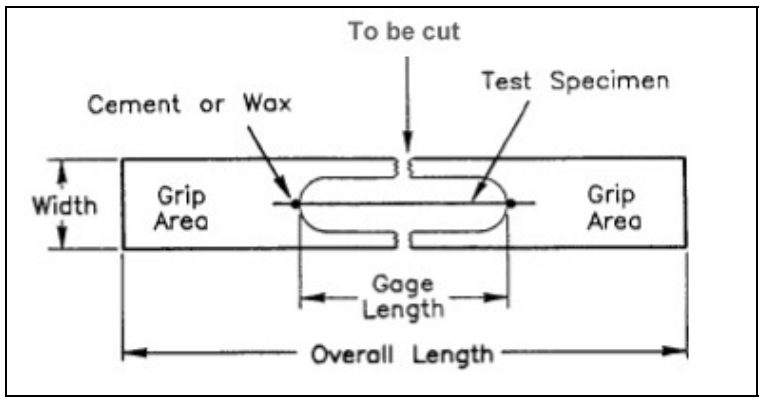

Fig. 2. Preparation of the tensile test specimens

The tensile test used Pearson Panke machine at Materials Laboratory Department of Mechanical and Industrial Engineering UGM. Natural fibers generally have a non-uniform cross-sectional shape. A variation on the physical form of fiber may affect the fiber cross-sectional area. Tensile test specimens that have been tested tensile fiber was then printed in resin to facilitate observation of the cross section fiber using a microscope and photographed. The photos were then transferred to a computer for the cross-sectional area was measured using Image Pro calibrated prior notice. The fiber diameter and fiber cross-sectional area average are calculated using the equation by ASTM D 3379.

\section{F. Test Pull-Out}

The pull-out test was carried out to determine the direct interaction fiber-matrix interface area and failure behavior of fiber-matrix due to the compatibility of two different materials. 


\section{RESULT AND DISCUSSION}

\section{A. Physical analysis}

Physical and chemical treatment have resulted in a change in the surface structure of Snake Fruit fiber. The raw material of Snake Fruit frond single fiber has beige color and micrometer scale in dimension. Further, a change of light brown color on the single fiber is resulted by treating with both water immersion and alkali (sodium hydroxyl) as seen in Figure 3. Next, the color is relatively different that showed on results of treatment with steaming. It produces dark brown color. The different color indicates that there is a transform in the surface structure of the fiber after the treatments. The enhancement the content of alkali in the treatment shows an enhance in the strength of the color difference [7].

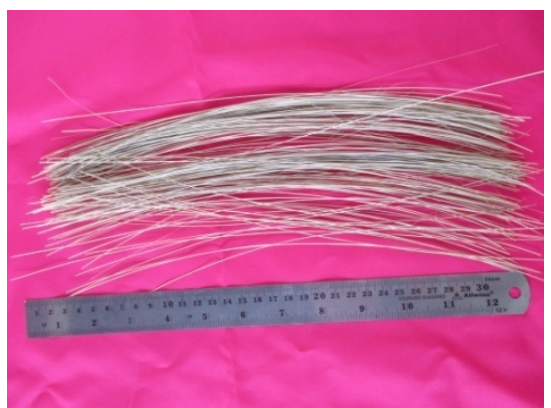

(a)

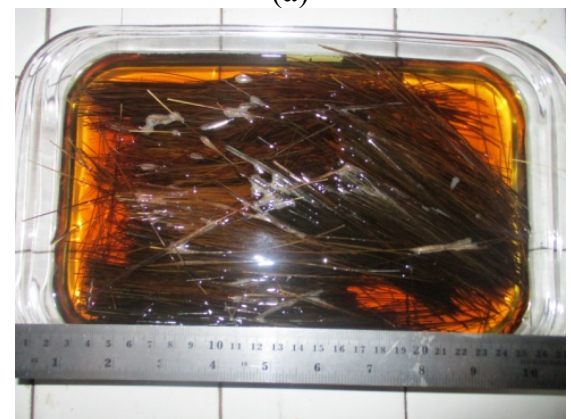

(c)

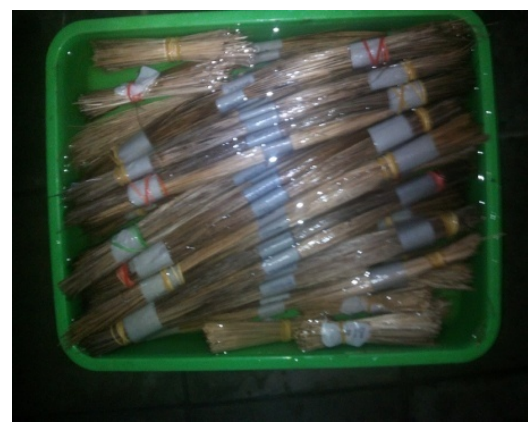

(b)

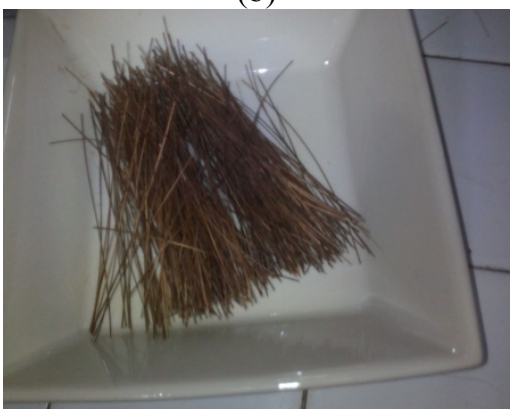

(d)

Fig. 3. Changes in the color of the fiber in some treatments. Single fiber frond pure Snake Fruit (a), fibers immersion in water (b), fibers with alkali treatment of $2 \%$ (c), fibers with alkali treatment of $2 \%$ and steaming (d).

\section{B. Chemical Analysis}

Table 1 shows substance arrangement of Snake Fruit single fiber before and after treatments. The alphacellulose proportion shows an increase when treated the alkali and alkali followed by steaming or steam explosion. This statement was also noted by Abraham et al. [9] who explained that there is an augment in the percentage of alpha-cellulose fiber jute which is subjected by steaming followed by the release of steam quickly. Deepa et al. [10] also support the argument that content of alpha-cellulose will increase on fiber that treated alkali followed steaming by the release of steam quickly.

TABLE 1. Composition of pure single fiber, after the alkali treatment, steaming, and steam exploded*

\begin{tabular}{|l|l|l|l|}
\hline & $\begin{array}{l}\text { Alfa cellulose } \\
\text { (\%) }\end{array}$ & $\begin{array}{l}\text { Hemicellulose } \\
\text { (\%) }\end{array}$ & $\begin{array}{l}\text { Lignin } \\
\text { (\%) }\end{array}$ \\
\hline Pure fiber & 47.18 & 31.89 & 22.27 \\
Alkali 3\% & 51.50 & 22.59 & 31.49 \\
Alkali 3\% + steaming & 54.53 & 18.83 & 26.33 \\
Alkali 3\% + steam explosion 10x & 54.34 & 21.83 & 22.58 \\
\hline
\end{tabular}

*Based on extracted free 


\section{Fourier Transfer-Infra Red (FTIR)}

As seen in Fig. 4, the investigation of the fiber using FTIR analysis shows that there is no basic change in the compositions of the fiber that treated at low alkali concentration by both untreated and $2 \%(\mathrm{w} / \mathrm{v})$ as seen in SA0T0, SA2T6, and followed by steaming (SA2T6S). This means that there is no principle change in the contents of the fiber. The change is only happening on the intensity of each group. Conversely, the trend shows slightly different on the fiber with treating at high alkali concentration by $8 \%(\mathrm{w} / \mathrm{v})$ and followed by steaming as seen in SA8T4S. Refer to the Table 1, this clearly seen that the change is by the percentage variations.

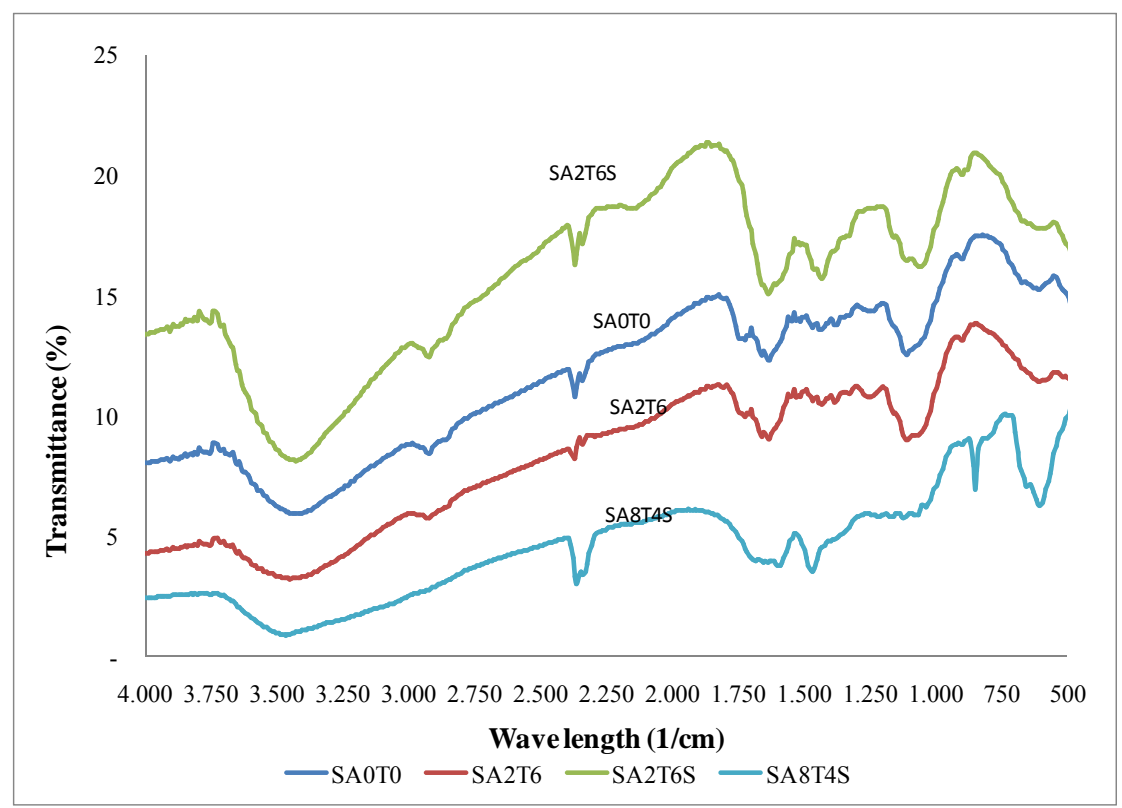

Fig. 4. FTIR Result

D. Scanning Electron Microscopy (SEM)

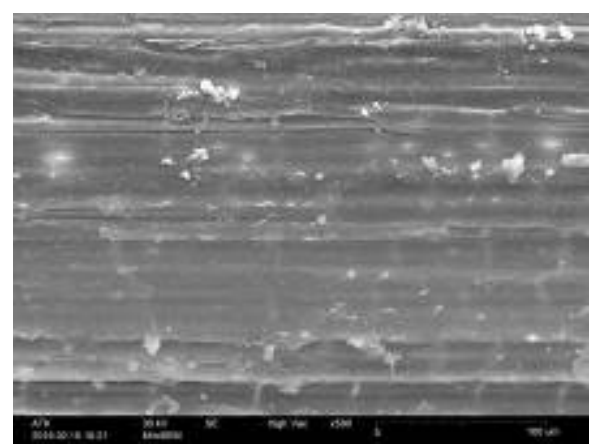

(a)

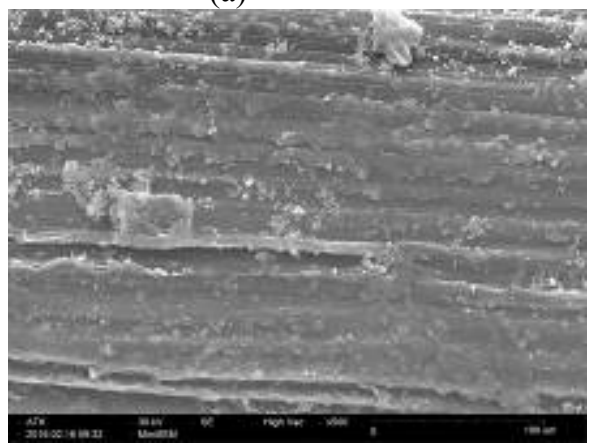

(c)

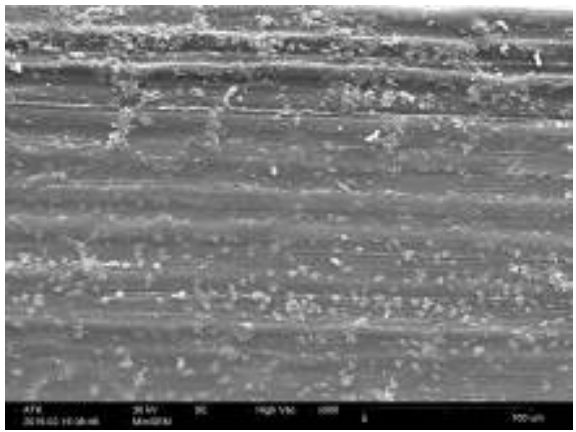

(b)

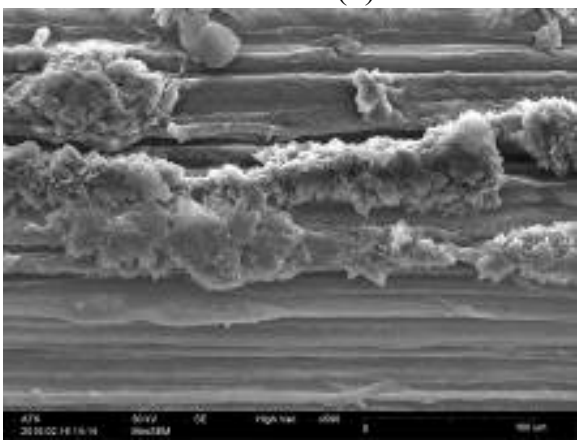

(d)

Fig. 5. SEM on fiber surface after treatments: (a) untreated fiber, (b) $2 \%$ of alkali, 6 hours and steaming, (c) $3 \%$ of alkali, 5 hours and steaming, and (d) $8 \%$ of alkali, 4 hours and steaming. 
The SEM photomicrograph, as seen in Fig. 5b, Fig. 5c and Fig. 5d, shows that the steaming treatment breaks the bonding of the fiber with other material as shown by the clearest border between each fiber layer. The broken parts of this fiber, which likely to be other than cellulose parts, will wash away during washing, resulted in the increase in Alfa cellulose percentage as presented in Table 1. Although the steaming treatment can break the bonding of the fiber, it is not effective to treat with higher alkali percentage as seen in Fig. 5d.

\section{E. Tensile Strength Analysis}

The variation in alkali content and time of immersion affects the mechanical properties of the fiber. It was illustrated that concentration of alkali clearly determines the fiber tensile strength. As shown in Fig. 6, the strength increases with increasing alkali contents until $2 \%$ of alkali contents and further, the enhancement in alkali contents tend to reduce tensile strength. That meant that the percentage of $2 \%$ is the optimum value for this case. The tensile strength, beginning from $160 \mathrm{MPa}$ for untreated fiber, rises as high as $275 \mathrm{MPa}$ at the best treatment point. The soaking time also influences the tensile strength. As shown in Fig. 6, the treatment in 6 hours gives a higher strength compared to that of 2 hours, 4 hours and 8 hours.

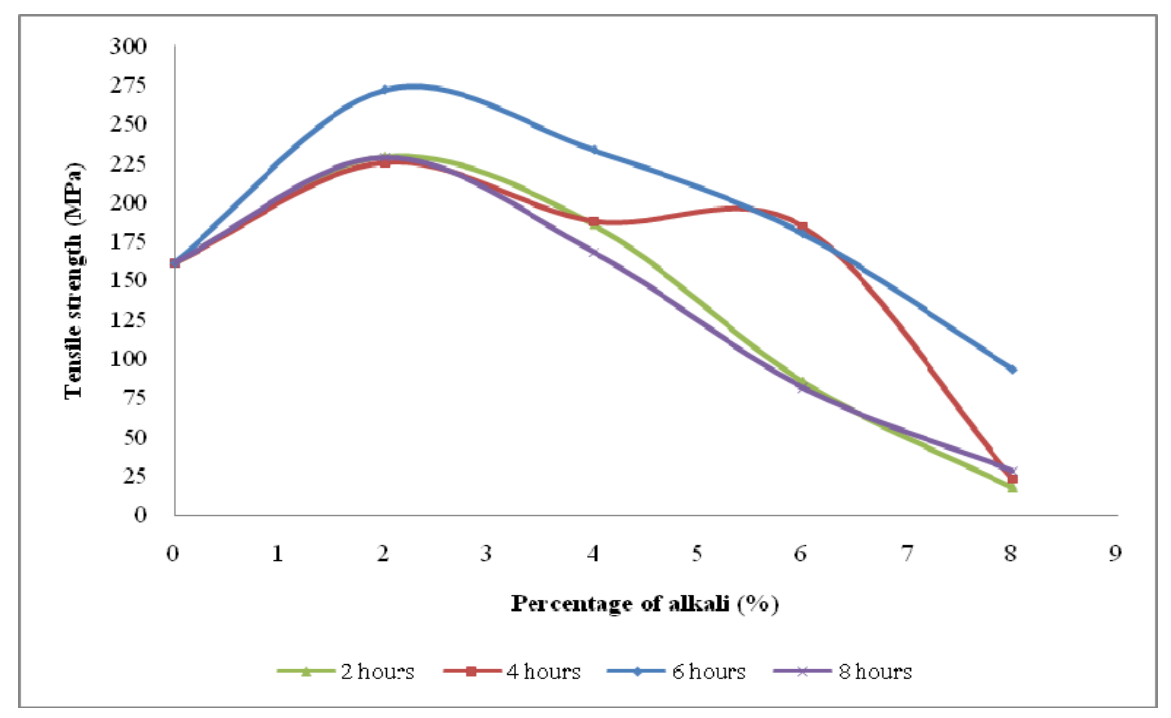

Fig. 6. Tensile strength vs alkali concentration

Effect of treatment of alkali on natural fibers in some research shows increased in mechanical properties in which research flax fibers treated with an alkaline composition of $5 \%$ on the variation of immersion time $0,2,4$, 6 hours showed that the strength and tensile strain composite has optimum value for the treatment of fibers for 2 hours at $190.27 \mathrm{MPa}$ and $0.44 \%$. Alkali treatment of the fiber coconut fiber would be the optimum composition of 5\% and 4 hours soaking time [11] and showed long soaking time decreases for high composition [12] [13]. Different patterns in spite of increased strain and Young's modulus, alkali treatment to a single fiber of coconut and Curauá (with the composition of $2 \%, 10 \%$ and $15 \%$ for 1 hour and 2 hours) resulted in a decrease in tensile strength [14] [15].

\section{F. Pull-Out Test}

Interfacial tension between the fibers with resin tends to decrease for the treated fibers on changes in the surface of the fibers and impurities are still attached to the fiber surface. Pull-out test by the polyester resin show shear stress of fiber without treatment reach 4.5 MPa higher than 3.9 MPa for fiber with treatment $2 \%$ of alkali and 2 bars in steaming. Effect of combination treatment with the alkali and steaming actually produce roughness on the surface of the fiber. The changes should improve the surface structure of the bonds between the fibers and the resin surface and further increase the interfacial tension. On the other hand, the presence of impurities fibers is still attached to the surface of the fiber shown in Fig. 5b, it will impede the penetration of the resin to the surface of the fiber and effect on interfacial tension.

\section{G. Diameter Reduction by Fibrillation}

Mechanical treatment by the steam explosion can affect the mechanism of fiber fibrillation. As shown in Fig. 7, the micrograph of steam exploded Snake Fruit frond shows fibrillation, which has taken place during the steam explosion process. There is fibrillation that is signed by reducing dimension from $300 \mu \mathrm{m}$ to $50 \mu \mathrm{m}$ in diameter. Mechanical treatment on steam-exploded hemp shaves shows defibrillation by SE severity $\operatorname{logR} 0=$ 4.45 allows to uncover the internal structure [16]. Application of steam explosion during mechanical treatment further removed the amorphous materials (lignin, hemicellulose, etc.) from the inner part of the fiber via depolymerisation and fibrillation [9]. Next the result of fibrillation of hemp fiber by the steam explosion has 
been classified into three variants and was fractionated through sieves with meshes of three sizes $(630 \mu \mathrm{m}$, $160 \mu \mathrm{m}$, and $63 \mu \mathrm{m})$. It results finest fibers with the diameters less than $63 \mu \mathrm{m}$ from $4 \%$ to $15 \%$ [17].

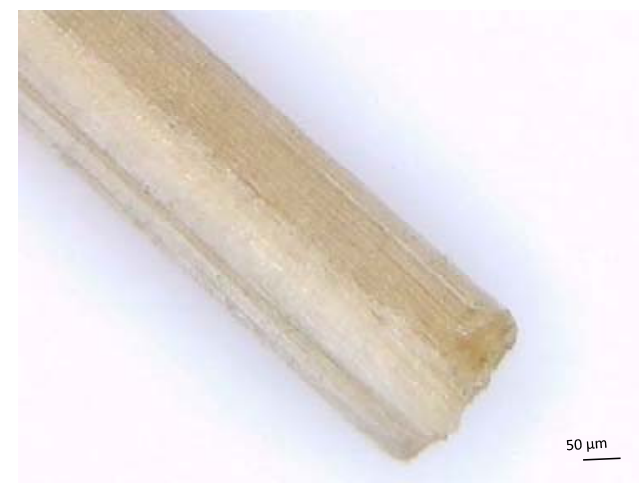

(a)

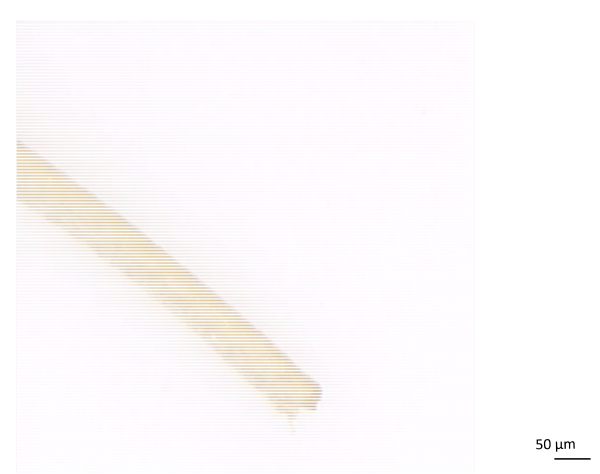

(b)

Fig. 7. Single fiber before (a) and after (b) explosion

The mechanism of steam penetration affects the mechanical properties of the fiber during the physical and mechanical treatments. It was noted that steaming and steam explosion on fiber tends to upgrade the fiber tensile strength. As shown in Fig. 8, the strength increases with combination treatment both alkali and steaming and alkali and steam explosion. The tensile strength, starting from $160 \mathrm{MPa}$ before treated, increases as high as 225 MPa with the alkali and steam explosion.

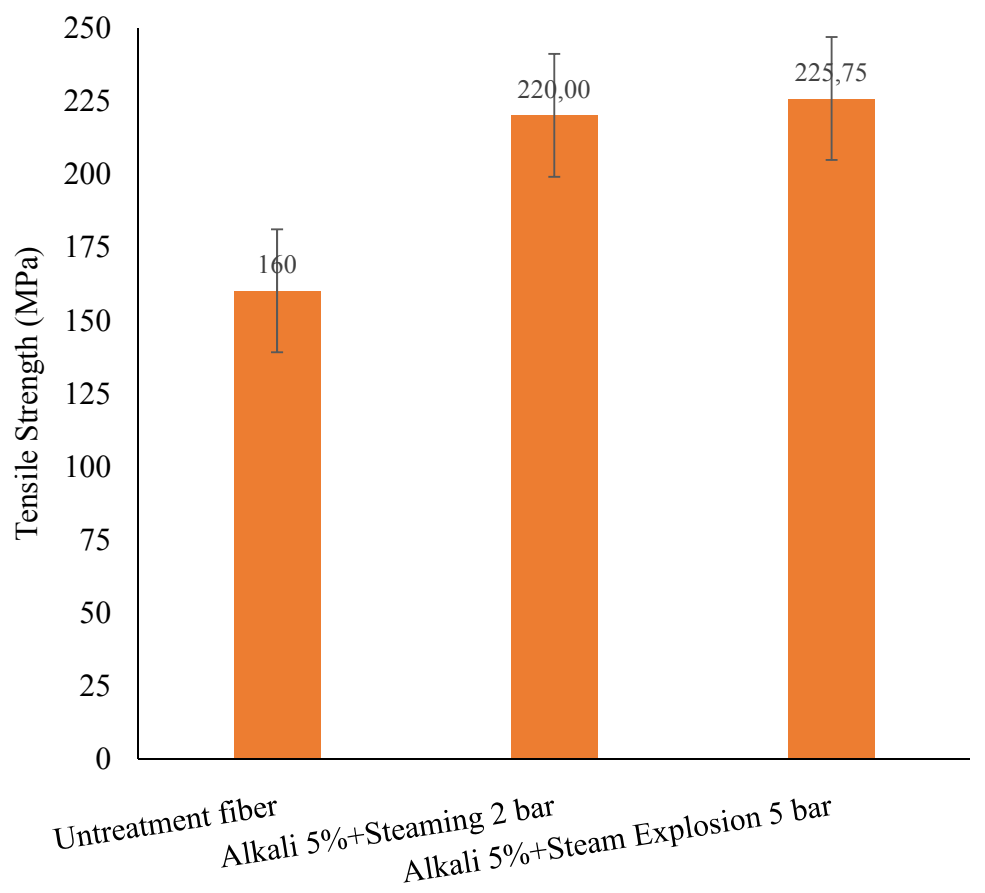

Fig. 8 . Tensile strength vs steaming and steam explosion treatments

\section{CONCLUSION}

Few treatments that consist of physical, chemical and mechanical treatment effect on removing the impurities of Snake Fruit frond fiber. Snake Fruit frond single fibers were subjected to alkali treatments with $2 \%-8 \%$ $\mathrm{NaOH}$ for $2-8$ hours to room temperature and steaming in $1-2$ bar. The tensile tests showed the alkali and steaming treatment resulted in the different tensile strength of Snake Fruit frond fiber compared without soaking. The highest tensile strength (275 MPa) was found at Snake Fruit frond fiber immersed in 2\% NaOH for 6 hours and steaming. These results show that the combination of alkali treatment and steaming can increase mechanical properties of Snake Fruit frond fiber. The strength also increases with combination treatment with starting from $160 \mathrm{MPa}$ before treated, increases as high as $225 \mathrm{MPa}$ with the alkali and steam explosion. These results show that the combination of alkali treatment, steaming and steam explosion can increase mechanical properties of Snake Fruit frond fiber. 


\section{ACKNOWLEDGMENT}

This work has been supported by Hibah Tim Pasca Sarjana, Ministry of Research, Technology and Higher Education, Republic Indonesia. The authors are grateful to the staff of Laboratory of Material Engineering, DTMI, Gadjah Mada University.

\section{REFERENCES}

[1] A. Schneider, "U. S. imports of asbestos brake material are on rise," Sunday Post-Dispatch, vol. 125, pp. 299, October 2003.

[2] P. J. Blau, "Compositions, Functions, and Testing of Friction Brake Materials and Their Additives," Energy, vol. 27, pp. 38, September 2001.

[3] Thongsang and N. Sombatsompop, "Effect Of Filler Surface Treatment on Properties of Fly Ash / Nr Blends," ANTEC, vol., pp. 3278-3282, 2005.

[4] B. Wang, "Pre-Treatment of Flax Fibers for Use in Rotationally Molded Bio composites," Master of Science thesis, University of Saskatchewan, Saskatoon, Canada, July 2004

[5] H. U. Zaman, M. A. Khan, R. A. Khan, and N. Sharmin, "Effect of chemical modifications on the performance of biodegradable photo cured coir fiber," Fibers Polym., vol. 12, pp. 727-733, April 2011.

[6] M. A. Khan, F. Mina, and L. T. Drzal, "Influence of Silane Coupling Agents of Different Functionalities on the Performance of JutePolycarbonate Composite," in 3rd International Wood and Natural Fibre Composites Symposium, 2000, paper 5, p 1-8.

[7] H. B. Öztürk and T. Bechtold, "Effect of NaOH Treatment on the Interfibrillar Swelling and Dyeing Properties of Lyocell (Tencel) Fibres," Fibres \& Textiles, vol. 15, pp. 114-117, January/December 2007.

[8] J. George, I. Van De Weyenberg, J. Ivens, and I. Verpoest, "Mechanical Properties of Flax Fibre Reinforced Epoxy Composites," in 2rd International Wood and Natural Fibre Composites Symposium, 1999, paper 8, p 1-8.

[9] E. Abraham, B. Deepa, L. A. Pothan, M. Jacob, S. Thomas, U. Cvelbar, and R. Anandjiwala, "Extraction of nanocellulose fibrils from lignocellulosic fibres: A novel approach," Carbohydr. Polym, vol. 86, pp. 1468-1475, Oct. 2011.

[10] B. Deepa, E. Abraham, B. M. Cherian, A. Bismarck, J. J. Blaker, L. A. Pothan, A. L. Leao, S. F. de Souza, and M. Kottaisamy, "Structure, morphology and thermal characteristics of banana nano fibers obtained by steam explosion.," Bioresour. Technol., vol. 102, pp. 1988-1997, Jan. 2011.

[11] S. Hemsri, K. Grieco, A. D. Asandei, and R. S. Parnas, "Composites : Part A, Wheat gluten composites reinforced with coconut fiber," Compos. Part A, vol. 43, pp. 1160-1168, February 2012.

[12] S. Jayabal, S. Velumani, P. Navaneethakrishnan, and K. Palanikumar, "Mechanical and Machinability Behaviors of Woven Coir FiberReinforced Polyester Composite," Fibers and Polymers, vol. 14, pp. 1505-1514, 2013.

[13] S. Jayabal, S. Sathiyamurthy, K. T. Loganathan, and S. Kalyanasundaram, "Effect of soaking time and concentration of NaOH solution on mechanical properties of coir - polyester composites," Bull. Mater. Sci., vol. 35, pp. 567-574, August 2012.

[14] F. Z. Arrakhiz, M. El Achaby, A. C. Kakou, S. Vaudreuil, K. Benmoussa, R. Bouhfid, O. Fassi-fehri, and A. Qaiss, "Mechanical properties of high density polyethylene reinforced with chemically modified coir fibers : Impact of chemical treatments," J. Mater., vol. 37, pp. 379-383, January 2012.

[15] A. Gomes, K. Goda, and J. Ohgi, "Effects of Alkali Treatment to Reinforcement on Tensile Properties of Curaua Fiber Green Composites," JSME International Journal Series A, vol 47, pp. 541-546, May 2004.

[16] A.Putniņa, S. Kukle and J. Grāvītis, "Extraction of highly purified microfibrils from the renewable resources by using green technology," Energetika, vol. 59, pp. 20-25, 2013.

[17] L. Grāve, A. Putniņa, S. Kukle, and V. Stramkale, "Steam Explosion Impact to Technical Hemp Fiber Diameter," in Proceedings of the 9th International Scientific and Practical Conference, 2013, paper 1,p. 112-115. 